\title{
Patient factors associated with 30-day morbidity, mortality, and length of stay after surgery for subdural hematoma: a study of the American College of Surgeons National Surgical Quality Improvement Program
}

\author{
Adam M. Lukasiewicz, MSc, ${ }^{1}$ Ryan A. Grant, MD, MS, ${ }^{2}$ Bryce A. Basques, MD, MHS, ${ }^{1}$ \\ Matthew L. Webb, AB, ${ }^{1}$ Andre M. Samuel, BBA, ${ }^{1}$ and Jonathan N. Grauer, MD ${ }^{1}$ \\ Department of ${ }^{1}$ Orthopaedics and Rehabilitation, and ${ }^{2}$ Neurosurgery, Yale School of Medicine, New Haven, Connecticut
}

\begin{abstract}
OBJECTIVE Surgery for subdural hematoma (SDH) is a commonly performed neurosurgical procedure. This study identifies patient characteristics associated with adverse outcomes and prolonged length of stay (LOS) in patients who underwent surgical treatment for SDH.
\end{abstract}

METHODS All patients in the American College of Surgeons National Surgical Quality Improvement Program (ACS NSQIP) who were treated via craniotomy or craniectomy for SDH between 2005 and 2012 were identified. Patient demographics, comorbidities, and 30-day outcomes were described. Multivariate regression was used to identify predictors of adverse events.

RESULTS A total of 746 surgical procedures performed for SDH were identified and analyzed. Patients undergoing this procedure were $64 \%$ male with an average age $( \pm$ SD) of $70.9 \pm 14.1$ years. The most common individual adverse events were death (17\%) and intubation for more than 48 hours (19\%). In total, 34\% experienced a serious adverse event other than death, $8 \%$ of patients returned to the operating room (OR), and the average hospital LOS was $9.8 \pm 9.9$ days. In multivariate analysis, reduced mortality was associated with age less than 60 years (relative risk $[R R]=0.47, p=0.017$ ). Increased mortality was associated with gangrene ( $R R=3.5, p=0.044)$, ascites $(R R=3.00, p=0.006)$, American Society of Anesthesiologists (ASA) Class 4 or higher $(R R=2.34, p=0.002)$, coma ( $R R=2.25, p<0.001)$, and bleeding disorders $(R R=$ $1.87, p=0.003$ ). Return to the OR was associated with pneumonia ( $R R=3.86, p=0.044)$, male sex $(R R=1.85, p=0.015)$, and delirium ( $R R=1.75, p=0.016$ ). Serious adverse events were associated with ventilator dependence preoperatively (RR $=1.86, p<0.001)$, dialysis $(R R=1.44, p=0.028)$, delirium $(R R=1.40, p=0.005)$, ASA Class 4 or higher $(R R=1.36, p=$ 0.035 ), and male sex (RR $=1.29, p=0.037$ ). Similarly, LOS was increased in ventilator dependent patients by 1.56 -fold $(p=$ 0.002 ), in patients with ASA Class 4 or higher by 1.30 -fold $(p=0.006)$, and in delirious patients by 1.29 -fold $(p=0.008)$.

CONCLUSIONS Adverse outcomes are common after surgery for SDH. In this study, $18 \%$ of the patients died within 30 days of surgery. Factors associated with adverse outcomes were identified. Patients and families should be counseled about the serious risks of morbidity and death associated with acute traumatic SDH requiring surgery.

http://thejns.org/doi/abs/10.3171/2015.2.JNS142721

KEY WORDS subdural hematoma; subdural hemorrhage; morbidity; in-hospital mortality; length of stay; NSQIP; vascular disorders

$\mathrm{S}$ UBDURAL hematoma (SDH) is a common condition confronting neurosurgeons, resulting in more than 90,000 hospitalizations annually. ${ }^{6}$ Morbidity, mortality, and length of stay (LOS) in patients treated with surgical evacuation of SDH are not well described, and the patient characteristics associated with adverse outcomes are not clearly established.
Positive outcomes following surgery for SDH have been demonstrated, particularly in young patients and in patients treated within 4 hours of injury. ${ }^{9,18,19}$ However, this population has a known significant risk of death. Historically, death after surgical evacuation of SDH has been reported in the range of $30 \%-60 \% .^{5,12,20,22}$ More recently, 3 groups have investigated the mortality risk of SDH using

ABBREVIATIONS ACS = American College of Surgeons; $\mathrm{ASA}=$ American Society of Anesthesiologists; $\mathrm{BMI}=$ body mass index; $\mathrm{CHF}=$ congestive heart failure; $\mathrm{CPT}=$ Current Procedural Terminology; DVT = deep venous thrombosis; ICD-9 = International Classification of Diseases, Ninth Revision; LOS = length of stay; MI = myocardial infarction; NIS = National Inpatient Sample; NSQIP = National Surgical Quality Improvement Project; OR = operating room; PE = pulmonary embolism; RR = relative risk; $\mathrm{SDH}=$ subdural hematoma.

SUBMITTED November 29, 2014. ACCEPTED February 3, 2015.

INCLUDE WHEN CITING Published online August 28, 2015; DOI: 10.3171/2015.2.JNS142721. 
data from the National Inpatient Sample (NIS) database, which is a representative sample of all US hospital admissions. These groups have found a mortality rate of $15 \%$ for traumatic SDH treated operatively, $7 \%$ for nontraumatic SDH treated operatively, and $12 \%$ for SDH overall., $4,6,10$

Although these above-noted NIS studies have clarified the modern risk of death associated with surgical evacuation of SDH in the US, the general health morbidity associated with surgical treatment of SDH has not been examined. However, the NIS database, while a valuable resource, only captures complications that occur during inpatient stays. Moreover, the accuracy of data about comorbidities and complications in this database is limited, as these data are pulled from the International Classification of Diseases, Ninth Revision (ICD-9) codes in administrative discharge summaries, rather than abstracted directly from charts. Consequently, patient comorbidities and adverse outcomes are generally underreported in the NIS compared with the American College of Surgeons National Surgical Quality Improvement Program (ACS NSQIP), as we have previously shown. ${ }^{2}$

To mitigate the limitations of the above studies, we analyzed data from the ACS NSQIP database. The ACS NSQIP is a national database that includes comorbidity and 30-day outcome data abstracted directly from patient charts based on published, standardized definitions. The ACS NSQIP specifically excludes patients with major trauma, who may have substantial morbidity and mortality related to generalized injury. Using these data, we examined LOS, surgical outcomes including return to the operating room (OR) and wound infection, and more general outcomes ranging from death to urinary tract infections.

Multivariate regression was used to determine patient comorbidities associated with adverse outcomes and prolonged LOS. The results of this study provide surgeons and intensive care unit practitioners with information to make detailed, accurate assessments of surgical risk, and to counsel patients and their families.

\section{Methods}

\section{Data Source}

The ACS NSQIP database, which compiles data from randomly selected surgical patients at more than 370 institutions in the US, was used for this study. ${ }^{1}$ This database includes more than 150 prospectively collected perioperative variables about included patients. ${ }^{11}$ Trained nurses abstract these data from medical records, operative reports, and patient interviews. Postoperative data are collected for 30 days after surgery for all patients, including discharged patients.

Patients who underwent craniotomy or craniectomy procedures for SDH between 2005 and 2012 were identified in the ACS NSQIP based on the following Current Procedural Terminology (CPT) codes: 61304, 61305, $61312,61313,61314$, and 61315 . The population of patients undergoing these procedures specifically for evacuation of SDH was identified using the ICD-9 codes for SDH (432.1, 852.2, and 852.3). Patients who also underwent aneurysm clipping procedures (CPT codes 61697, 61700, 61698, 61702, and 61703) or embolization (CPT codes 61624 and
61635) were excluded. A waiver of informed consent was granted by our institution's institutional review board.

\section{Data Collection}

Patient demographic characteristics, such as age, sex, height, and weight, were abstracted directly from charts into the ACS NSQIP. Body mass index (BMI) was derived from height and weight, and then categorized according to existing guidelines. ${ }^{16}$ Medical comorbidities and adverse events in the 30-day postoperative period were determined by abstracters based on published definitions. ${ }^{1}$

\section{Outcomes Measures}

The primary outcome measure was mortality. Secondary outcomes measured included the occurrence of adverse events other than death, which were grouped as severe adverse events, minor adverse events, and any adverse events, as described previously. ${ }^{3,7}$

Severe adverse events were considered to be prolonged intubation of 48 hours or more, return to the OR, unplanned reintubation, sepsis, venous thromboembolism, coma, stroke, cardiac arrest, septic shock, myocardial infarction (MI), infection of the surgical site or organ space, and acute renal failure. Minor adverse events were considered to be perioperative blood transfusion, urinary tract infection, pneumonia, renal insufficiency, and wound dehiscence. For data reporting, we defined "any adverse event" as the occurrence of at least 1 major or minor adverse event. Each patient was only counted once for each adverse event category, regardless of the number of adverse events in total for a given patient.

Return to the OR was also evaluated as a separate outcome measure. Severe and minor adverse events were considered separately from death because of the high case mortality in this population, which caused concern that death would drive the analysis if death and other adverse events were analyzed together. Lastly, the ACS NSQIP calculates LOS based on admission and discharge dates, so stays longer than 30 days are recorded. However, outcomes are only captured for the first 30 days.

\section{Statistical Analysis}

Statistical analyses were performed using $\mathrm{R}$ version 3.1.2. Statistical significance was determined by a 2 -tailed $\alpha$ of 0.05 . Univariate regressions were performed to assess the relationships between comorbidities and death. Multivariate Poisson regression, with robust sandwich errors, was used to determine the effect of patient factors on mortality, return to the OR, adverse events, and LOS. ${ }^{21}$ Age, BMI, sex, and all predictors significant in the univariate regression were included in the multivariate model. Functional status and drinking status were not evaluated as predictors because these variables had large proportions of missing data. For continuous variables, means are reported with standard deviations.

\section{Results}

\section{Patient Demographics and Comorbidities}

A total of 746 patients who underwent evacuation of SDH were included in the ACS NSQIP between 2005 and 
TABLE 1. Summary of patient demographics

\begin{tabular}{|c|c|c|}
\hline Variable & No. & $(\%)$ \\
\hline Total no. of cases & 746 & 100 \\
\hline \multicolumn{3}{|l|}{ Age (yrs) } \\
\hline $18-59$ & 156 & 21 \\
\hline $60-69$ & 159 & 21 \\
\hline $70-79$ & 193 & 26 \\
\hline $80+$ & 238 & 32 \\
\hline \multicolumn{3}{|l|}{ BMI } \\
\hline$<18.5$ & 26 & 4 \\
\hline $18.5-25$ & 242 & 36 \\
\hline $25-30$ & 250 & 37 \\
\hline $30-35$ & 101 & 15 \\
\hline$>35$ & 54 & 8 \\
\hline Male & 479 & 64 \\
\hline Female & 267 & 36 \\
\hline \multicolumn{3}{|l|}{ ASA Class } \\
\hline 1 & 2 & 0 \\
\hline 2 & 51 & 7 \\
\hline 3 & 322 & 43 \\
\hline 4 & 318 & 43 \\
\hline 5 & 51 & 7 \\
\hline \multicolumn{3}{|l|}{ Functional Status } \\
\hline Independent & 281 & 57 \\
\hline Partially dependent & 97 & 20 \\
\hline Totally dependent & 111 & 23 \\
\hline \multicolumn{3}{|l|}{ Alcohol Abuse } \\
\hline Yes & 51 & 9 \\
\hline No & 500 & 91 \\
\hline
\end{tabular}

2012. Data for 196 of these patients were substantially missing, so they were not included in the multivariate analysis. Table 1 shows patient demographics and comorbidities.

The average patient age $( \pm$ SD) was $70.9 \pm 14.1$ years, and $64 \%$ of patients were male. In terms of functional status, $57 \%$ of patients were functionally independent prior to surgery. In terms of BMI, $73 \%$ were within normal or overweight classes, and $23 \%$ were obese. American Society of Anesthesiologists (ASA) Class 3 or 4 was noted in $43 \%$ of patients each. Nine percent of patients with data available consumed more than 2 alcoholic drinks per day in the 2 weeks prior to surgery.

\section{Comorbidities}

The comorbidities present in this population and the mortality associated with each condition are shown in Table 2 . The most common comorbidity was hypertension (69\% of patients), followed by delirium/confusion $(43 \%)$, and bleeding disorder (29\%).

The preoperative factors found to be significantly associated with mortality in the univariate analysis and included in the multivariate analysis were ascites $(67 \%, \mathrm{p}$ $=0.0014)$, gangrene $(67 \%, \mathrm{p}=0.0428)$, pneumonia $(63 \%$, $\mathrm{p}=0.0024)$, coma $(62 \%, \mathrm{p}<0.0001)$, dialysis $(50 \%, \mathrm{p}<$ $0.0001)$, history of MI $(50 \%, \mathrm{p}=0.0326)$, ventilator de-
TABLE 2. Summary of patient comorbidities

\begin{tabular}{|c|c|c|c|c|}
\hline Comorbidities & No. & $(\%)^{*}$ & $\begin{array}{l}\text { Mortality } \\
(\%)\end{array}$ & $\begin{array}{c}p \\
\text { Value† }\end{array}$ \\
\hline Hypertension & 515 & 69 & 18 & 0.4975 \\
\hline Delirium/confusion & 237 & 43 & 26 & 0.0016 \\
\hline Bleeding disorder & 219 & 29 & 32 & 0.0000 \\
\hline History of stroke & 155 & 28 & 27 & 0.0091 \\
\hline Ventilator dependence & 140 & 19 & 48 & 0.0000 \\
\hline Diabetes & 123 & 16 & 28 & \\
\hline Insulin & 47 & 6 & 30 & 0.1830 \\
\hline Non-insulin & 76 & 10 & 28 & 0.1870 \\
\hline Hemiparesis & 119 & 16 & 17 & 0.2974 \\
\hline Smoking & 103 & 14 & 11 & 0.0520 \\
\hline History of cardiac op & 87 & 12 & 23 & 0.4212 \\
\hline Coma & 69 & 13 & 62 & 0.0000 \\
\hline $\begin{array}{l}\text { History of percutaneous } \\
\text { coronary intervention }\end{array}$ & 64 & 9 & 27 & 0.1390 \\
\hline Dyspnea & 52 & 7 & 35 & \\
\hline Moderate - exertion & 26 & 3 & 23 & 0.3558 \\
\hline Severe - at rest & 26 & 3 & 46 & 0.0001 \\
\hline Preop open wound & 48 & 6 & 29 & 0.0266 \\
\hline COPD & 41 & 5 & 22 & 0.4327 \\
\hline Dialysis & 30 & 4 & 50 & 0.0000 \\
\hline History of TIA & 26 & 3 & 19 & 0.9153 \\
\hline $\begin{array}{l}\text { Oral steroid use in } \\
30 \text { days prior to op }\end{array}$ & 23 & 3 & 22 & 0.5803 \\
\hline History of CHF & 19 & 3 & 42 & 0.0040 \\
\hline PVD & 19 & 3 & 32 & 0.1736 \\
\hline Disseminated cancer & 16 & 2 & 31 & 0.1410 \\
\hline Paraplegia & 12 & 2 & 17 & 0.7573 \\
\hline CNS tumor & 9 & 1 & 11 & 0.4765 \\
\hline Weight loss & 9 & 1 & 22 & 0.7032 \\
\hline Pneumonia & 8 & 1 & 63 & 0.0024 \\
\hline History of MI & 8 & 1 & 50 & 0.0326 \\
\hline Ascites & 6 & 1 & 67 & 0.0014 \\
\hline Angina & 5 & 1 & 20 & 1.0000 \\
\hline Quadriplegia & 4 & 1 & 25 & 0.7905 \\
\hline Gangrene & 3 & 1 & 67 & 0.0428 \\
\hline Renal failure & 2 & 0 & 0 & 0.5160 \\
\hline
\end{tabular}

COPD = chronic obstructive pulmonary disease; $P V D=$ peripheral vascular disease; $\mathrm{TIA}=$ transient ischemic attack.

* The proportion of patients with a condition, excluding patients with missing data for that condition. The degree of missing data varied between comorbidities.

† Statistically significant $p$ values are in bolded text.

pendence $(48 \%, \mathrm{p}<0.0001)$, severe dyspnea $(46 \%, \mathrm{p}=$ $0.0001)$, history of congestive heart failure $(\mathrm{CHF} ; 42 \%, \mathrm{p}=$ $0.0040)$, bleeding disorder $(32 \%, \mathrm{p}<0.0001)$, preoperative open wound $(29 \%, \mathrm{p}=0.0266)$, history of stroke $(27 \%, \mathrm{p}=$ $0.0091)$, and delirium $(26 \%, \mathrm{p}=0.0016)$.

\section{Postoperative Adverse Events}

Death within 30 days of surgery was a common adverse 
event, occurring in 130 patients (17\%). The proportion of patients surviving each day following surgery is shown as a Kaplan-Meier curve (Fig. 1). The decrease in survivorship decelerates over time from about $2 \%$ per day between Days 0 and 1 to $0.1 \%$ per day at 4 weeks.

Table 3 elucidates postoperative adverse events. Mechanical ventilation for 48 hours or more was the single most common adverse event, occurring in 144 patients $(19 \%)$. Of those patients intubated for more than 2 days, $47 \%$ eventually died. Fifty-eight patients (8\%) were brought back to the OR for reevacuation of the SDH. Unplanned reintubation and sepsis occurred in 47 (6\%) and $46(6 \%)$ patients, respectively. The other severe adverse events, such as deep venous thrombosis (DVT)/pulmonary embolism (PE), coma, stroke, cardiac arrest or MI, and septic shock occurred relatively rarely, arising in $4 \%$ or less of cases. Overall, 256 patients (34\%) experienced a severe postoperative event aside from death.

A total of 194 patients (26\%) experienced a minor adverse event. The most common minor event was perioperative blood transfusion, which accounted for more than half of minor events (107 cases, 14\%). Urinary tract infection and pneumonia occurred in 9\% (64 cases) and 8\% (58 cases), respectively. Progressive renal failure occurred in 7 patients (1\%). Any adverse event including death occurred in 356 patients (48\%), and any adverse event aside from death occurred in 332 patients $(45 \%)$.

\section{Length of Stay}

The average LOS in the hospital for all patients was 9.8 \pm 9.9 days. In patients who survived, the average LOS was $10.3 \pm 10.6$ days. Figure 2 is a histogram showing the LOS in patients who survived. Ninety-one percent of patients were inpatient for fewer than 3 weeks, but some patients had very long admissions (up to 71 days).

\section{Predictors of Adverse Events}

The results of multivariate regression to identify predictors of adverse events are shown in Table 4. For each of the studied outcomes (death, return to the OR, severe adverse event, any adverse event, and LOS), a separate multivariate analysis was conducted.

The risk of death was approximately $50 \%$ in patients

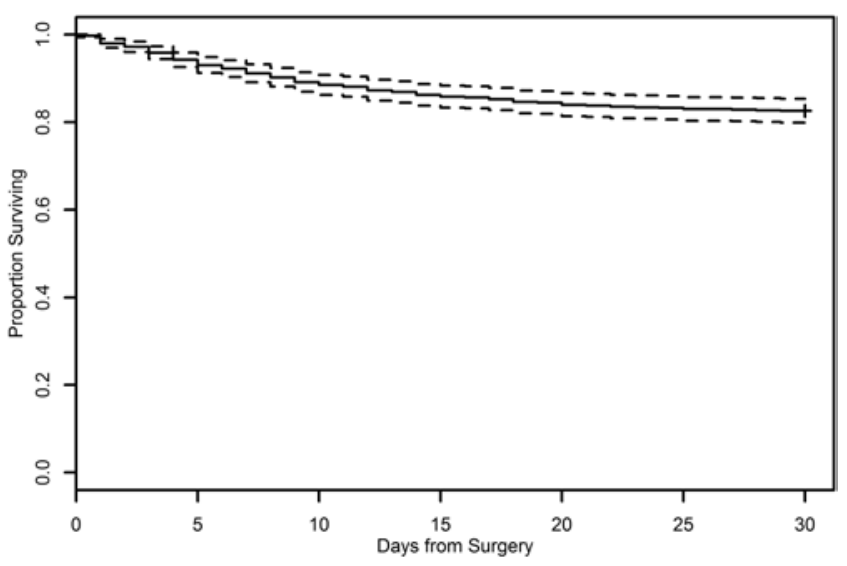

FIG. 1. Kaplan-Meier curve showing survivorship after surgery. Dashed lines represent $95 \%$ confidence intervals.
TABLE 3. Summary of postoperative adverse events

\begin{tabular}{lcc}
\hline \multicolumn{1}{c}{ Variable } & No. & $(\%)$ \\
\hline Death & 130 & 17 \\
\hline Any adverse event $^{*}$ & 332 & 45 \\
\hline Severe adverse event $^{*}$ & 256 & 34 \\
\hline Ventilator $>48$ hrs $^{*}$ Return to OR & 144 & 19 \\
\hline Unplanned reintubation & 58 & 8 \\
\hline Sepsis & 47 & 6 \\
\hline DVT/PE & 46 & 6 \\
\hline Coma & 31 & 4 \\
\hline Stroke & 30 & 4 \\
\hline Cardiac arrest & 16 & 2 \\
\hline Septic shock & 13 & 2 \\
\hline Ml & 12 & 2 \\
\hline Surgical site or deep infection & 9 & 1 \\
\hline Acute renal failure & 6 & 1 \\
\hline Minor adverse event & 2 & 0 \\
\hline Perioperative transfusion & 194 & 26 \\
\hline Urinary tract infection & 107 & 14 \\
\hline Pneumonia & 64 & 9 \\
\hline Progressive renal insufficiency & 7 & 8 \\
\hline
\end{tabular}

* Including all relevant complications except death.

less than 60 years old compared with those who were 60 69 (relative risk $[R R]=0.47, p=0.017$ ). Increased postoperative mortality was associated with gangrene $(\mathrm{RR}=$ $3.50, \mathrm{p}=0.044)$, ascites $(\mathrm{RR}=3.00, \mathrm{p}=0.006)$, ASA Class 4 or higher $(R R=2.34, p=0.002)$, coma $(R R=2.25, p<$ $0.001)$, dialysis $(\mathrm{RR}=1.93, \mathrm{p}=0.034)$, and bleeding disorders $(\mathrm{RR}=1.87, \mathrm{p}=0.003)$.

Increased risk of requiring repeat surgery was associated with preoperative pneumonia $(\mathrm{RR}=3.86, \mathrm{p}=0.044)$, male sex $(R R=1.85, p=0.015)$, and delirium $(R R=1.75$,

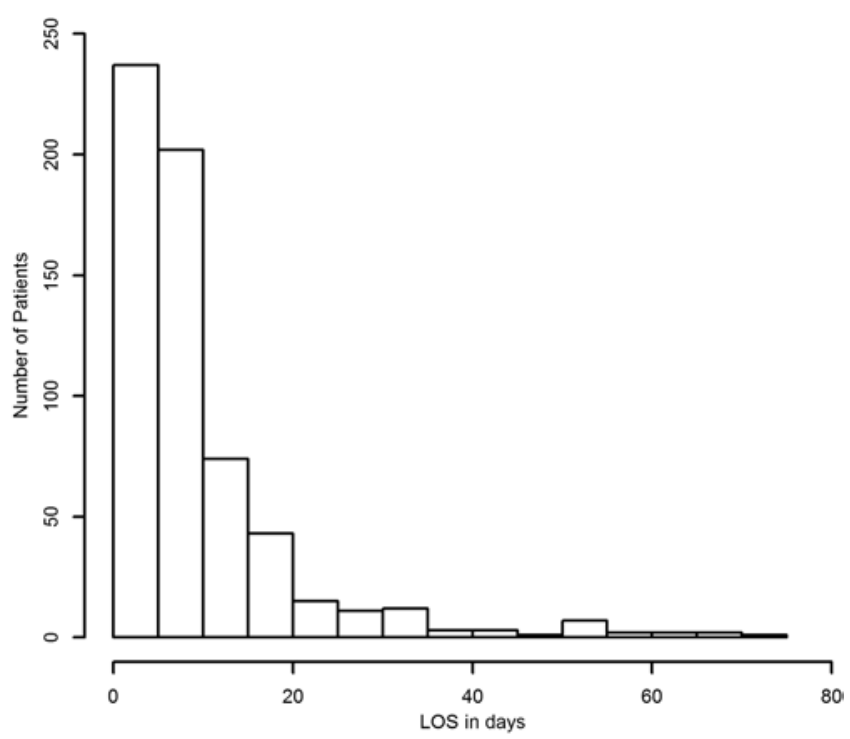

FIG. 2. Histogram of LOS for surviving patients. 
TABLE 4. Association of patient factors and outcomes*

\begin{tabular}{|c|c|c|c|c|c|c|c|c|c|c|}
\hline \multirow[b]{2}{*}{ Patient Factor } & \multicolumn{2}{|c|}{ Death } & \multicolumn{2}{|c|}{ Return to OR } & \multicolumn{2}{|c|}{$\begin{array}{c}\text { Severe } \\
\text { Complication† }\end{array}$} & \multicolumn{2}{|c|}{$\begin{array}{c}\text { Any } \\
\text { Complication† }\end{array}$} & \multicolumn{2}{|c|}{ LOS $\ddagger$} \\
\hline & $\mathrm{RR}$ & p Value & RR & $p$ Value & $\mathrm{RR}$ & $p$ Value & $\mathrm{RR}$ & $p$ Value & MC & $p$ Value \\
\hline \multicolumn{11}{|l|}{ Age (yrs) } \\
\hline $18-59$ & 0.47 & 0.017 & 1.09 & 0.798 & 0.89 & 0.468 & 0.86 & 0.298 & 1.10 & 0.464 \\
\hline $60-69$ & \multicolumn{2}{|c|}{ Reference } & \multicolumn{2}{|c|}{ Reference } & \multicolumn{2}{|c|}{ Reference } & \multicolumn{2}{|c|}{ Reference } & \multicolumn{2}{|c|}{ Reference } \\
\hline $70-79$ & 0.82 & 0.425 & 0.78 & 0.422 & 0.79 & 0.128 & 0.93 & 0.527 & 1.12 & 0.318 \\
\hline$>80$ & 1.23 & 0.373 & 0.64 & 0.183 & 0.88 & 0.418 & 0.98 & 0.841 & 1.10 & 0.435 \\
\hline Male sex & 1.16 & 0.407 & 1.85 & 0.015 & 1.29 & 0.037 & 1.01 & 0.929 & 1.06 & 0.482 \\
\hline \multicolumn{11}{|l|}{ BMI } \\
\hline$<18.5$ & 1.96 & 0.065 & 1.14 & 0.834 & 1.24 & 0.367 & 1.05 & 0.813 & 1.00 & 0.985 \\
\hline $18.5-25$ & \multicolumn{2}{|c|}{ Reference } & \multicolumn{2}{|c|}{ Reference } & \multicolumn{2}{|c|}{ Reference } & \multicolumn{2}{|c|}{ Reference } & \multicolumn{2}{|c|}{ Reference } \\
\hline $25-30$ & 1.02 & 0.912 & 1.35 & 0.235 & 1.14 & 0.296 & 0.99 & 0.917 & 1.01 & 0.922 \\
\hline $30-35$ & 1.25 & 0.396 & 0.98 & 0.962 & 0.90 & 0.569 & 0.74 & 0.050 & 1.00 & 0.989 \\
\hline$>35$ & 0.59 & 0.205 & 0.96 & 0.919 & 0.86 & 0.484 & 0.79 & 0.203 & 0.83 & 0.221 \\
\hline ASA Class 4+ & 2.34 & 0.002 & 1.42 & 0.165 & 1.36 & 0.035 & 1.33 & 0.013 & 1.30 & 0.006 \\
\hline Ascites & 3.00 & 0.006 & 0.86 & 0.860 & 1.19 & 0.504 & 0.98 & 0.950 & 1.03 & 0.793 \\
\hline Bleeding disorder & 1.87 & 0.003 & 0.97 & 0.907 & 1.17 & 0.207 & 1.30 & 0.004 & 1.05 & 0.603 \\
\hline Coma & 2.25 & $<0.001$ & 1.01 & 0.979 & 0.88 & 0.385 & 0.90 & 0.350 & 1.07 & 0.680 \\
\hline History of CHF & 0.79 & 0.522 & 0.79 & 0.687 & 1.20 & 0.491 & 1.19 & 0.298 & 1.37 & 0.264 \\
\hline Delirium/confusion & 1.02 & 0.923 & 1.75 & 0.016 & 1.40 & 0.005 & 1.23 & 0.024 & 1.29 & 0.008 \\
\hline Dialysis & 1.93 & 0.034 & 1.80 & 0.148 & 1.44 & 0.028 & 1.41 & 0.004 & 1.37 & 0.122 \\
\hline Disseminated cancer & 1.50 & 0.390 & 0.60 & 0.630 & 1.25 & 0.506 & 0.95 & 0.885 & 1.33 & 0.534 \\
\hline \multicolumn{11}{|l|}{ Dyspnea } \\
\hline Moderate & 1.12 & 0.780 & 2.00 & 0.099 & 0.92 & 0.787 & 0.92 & 0.735 & 1.14 & 0.675 \\
\hline Severe & 1.73 & 0.103 & 0.79 & 0.684 & 0.78 & 0.464 & 0.77 & 0.319 & 1.61 & 0.119 \\
\hline Gangrene & 3.50 & 0.044 & \multicolumn{2}{|c|}{ No return to OR } & 1.07 & 0.892 & 0.89 & 0.822 & 1.38 & 0.119 \\
\hline History of Ml & 0.43 & 0.454 & \multicolumn{2}{|c|}{ No return to OR } & 0.86 & 0.806 & 1.14 & 0.716 & 0.87 & 0.750 \\
\hline Open wound & 0.89 & 0.722 & 1.62 & 0.167 & 1.04 & 0.874 & 1.01 & 0.964 & 0.80 & 0.222 \\
\hline Pneumonia & 1.18 & 0.804 & 3.86 & 0.044 & 0.97 & 0.960 & 1.00 & 0.995 & 0.44 & 0.079 \\
\hline Stroke & 1.05 & 0.770 & 0.92 & 0.731 & 1.24 & 0.061 & 1.18 & 0.065 & 1.21 & 0.059 \\
\hline Ventilator dependence & 1.64 & 0.070 & 0.62 & 0.223 & 1.86 & $<0.001$ & 1.62 & $<0.001$ & 1.56 & 0.002 \\
\hline
\end{tabular}

$M C=$ Multiplicative change in LOS compared to reference level; OR = operating room.

* Relative risk (RR) was adjusted for all factors included in this table. Statistically significant $p$ values are in bolded text.

$\dagger$ Not including death as a severe complication or in any complication.

$\ddagger$ Length of stay for those patients who survived.

$\mathrm{p}=0.016)$. No patients among the small numbers of those with gangrene and MI returned to the OR for repeat surgery, so these comorbidities were excluded from the multivariate regression for this outcome.

Greater risk of a severe adverse event was associated with ventilator dependence $(\mathrm{RR}=1.86, \mathrm{p}<0.001)$, dialysis $(R R=1.44, p=0.028)$, delirium $(R R=1.40, p=$ $0.005)$, ASA Class 4 or higher $(R R=1.36, p=0.035)$, and male sex $(R R=1.29, p=0.037)$. Similarly, the occurrence of any adverse event was associated with ventilator dependence ( $R R=1.62, p<0.001)$, dialysis $(R R=1.41, p$ $=0.004)$, ASA Class 4 or higher $(\mathrm{RR}=1.33, \mathrm{p}=0.013)$, bleeding disorder $(\mathrm{RR}=1.30, \mathrm{p}=0.004)$, and delirium $(\mathrm{RR}=1.23, \mathrm{p}=0.024)$.

Significantly longer LOS was noted with ventilator dependence $(1.56$-fold, $\mathrm{p}=0.002)$, ASA Class 4 or higher (1.30-fold, $\mathrm{p}=0.006)$, and delirium (1.29-fold, $\mathrm{p}=0.008)$.

\section{Discussion}

Surgical evacuation of SDH is a common and effective neurosurgical procedure. ${ }^{14,17}$ However, short-term health outcomes of the procedure, aside from death and recurrence, have not been well characterized. We studied a national sample of 746 patients who underwent surgical drainage of SDH between 2005 and 2012, and describe in detail the comorbidities, adverse postoperative events, and predictors of adverse events in this population. These findings should help neurosurgeons, intensivists, and traumatologists in their decision making and in counseling patients and their families.

\section{Patient Population}

Previous database studies have distinguished between "nontraumatic" and "traumatic" SDH based on ICD-9 
codes. ${ }^{4,10}$ However, nontraumatic SDH in this context does not represent true spontaneous hemorrhage, but rather an SDH without a documented known injury. Hence, despite the difference in coding, these patients were considered together in this study. Those patients with coding evidence of aneurysms or other inciting causes of SDH were excluded. Because the ACS NSQIP does not collect data on patients presenting with major trauma, the patient population studied here is therefore patients with SDH caused by relatively minor injury.

Patients undergoing surgery for SDH generally have several comorbidities. Not surprisingly, nearly $70 \%$ of patients have hypertension treated with medication. More than $40 \%$ of patients had preexisting delirium/confusion, and $20 \%$ of patients were ventilator dependent. Bleeding disorders were present in about $30 \%$ of patients, and diabetes and history of stroke both had prevalences slightly higher than $20 \%$.

\section{Mortality Rate}

In total, 130 patients in this study died, which equates to a $17 \%$ 30-day mortality rate. This is similar to the $15 \%$ operatively treated traumatic SDH mortality rate, but substantially higher than the $7 \%$ operatively treated nontraumatic SDH mortality rate from NIS data. ${ }^{4,10}$ The most likely explanation for this more than 2-fold difference is that NIS only captures inpatient mortality, whereas NSQIP captures all deaths within 30 days, including at home, in rehabilitation facilities, and in hospices. ${ }^{1}$ In addition, the distinction between a traumatic and a nontraumatic SDH based on ICD-9 coding appears dubious, as truly nontraumatic SDH is a rare condition. ${ }^{15}$ The selection of codes may reflect the presence of an identifiable, recent trauma in the history rather than the actual underlying cause of bleeding.

The rate at which patients died was greatest immediately following surgery, and decreased with time. At 4 weeks, survivorship decreased by about $0.1 \%$ per day compared with $2 \%$ per day in the immediate postoperative period. Approximately $50 \%$ of patient deaths occurred within 1 week, $80 \%$ within 2 weeks, and more than $90 \%$ by 3 weeks. The Kaplan-Meier curve suggests that survivorship is asymptotically approaching a plateau near $80 \%$.

\section{Length of Stay}

The average LOS for patients who did not die was about 10 days. While almost $95 \%$ of patients were discharged within 1 month, a few patients did have exceptionally long stays of more than 2 months. Nevertheless, the average LOS in this study is shorter than previously published estimates of 15-20 days. ${ }^{8}$

\section{Adverse Events}

Surgeons performing SDH evacuation need to be aware of the high rate of adverse events because more than onethird of patients experienced a severe adverse event other than death. The most common severe adverse event was ventilator dependence for more than 2 days. More importantly, these ventilator-dependent patients ultimately died in nearly $50 \%$ of cases. In terms of reoperation, repeat surgery was required in 58 cases $(8 \%)$, consistent with previous estimates. ${ }^{4,13}$

It should be noted that as with comorbidities, many of the adverse events described here could be ascribed more to the natural history of SDH rather than to surgical intervention, and these outcomes could occur more frequently without intervention. The order of causation-that is, which comes first-is unknown, but the associations are present.

\section{Predictors of Mortality}

In the multivariate model for death, mortality was significantly associated with the presence of ascites, coma prior to surgery, coagulopathy, and dialysis. These results are logical and reasonably suggest that death following SDH is influenced both by the extent of neurological damage and the overall health of the patient at the time of surgery. Whereas coma prior to surgery may, in many cases, reflect the severity of SDH, ascites and dialysis are both markers for poor general health. Similarly, bleeding disorders would worsen any intracranial bleeding, and the exact type of bleeding disorder is beyond the scope of the NSQIP. ASA class was significantly associated with mortality, even when controlling for other morbidities, demonstrating the value of the anesthesiologist's assessment of the patient preoperatively. Lastly, an age less than 60 years was protective against death, as expected. ${ }^{9}$

ASA class, delirium, and ventilator dependence were associated with increased LOS and complications other than death. For ventilator dependence, this effect is likely explained both by overall poor health and by the inclusion of mechanical ventilation after surgery for longer than 48 hours as a complication. Male sex was associated with a greater risk of returning to the OR and a higher risk of severe adverse events, likely from a more significant intracranial injury.

The risk factors identified in this study are unsurprising, based on current clinical wisdom and previous work. However, some patient factors that might be expected to influence morbidity and mortality after SDH evacuation did not have a significant effect, such as metastatic cancer and advancing age. The magnitudes of the risks associated with various comorbidities have not been previously reported, and should help surgeons tailor estimates of risk to individual patients. A better understanding of the risk facing a patient will help surgeons in determining the appropriateness of surgical evacuation for $\mathrm{SDH}$, and to counsel patients and families.

\section{Limitations of the Study}

Our study was limited by the information available in the ACS NSQIP database. Some factors that could potentially affect outcomes, such as radiological information about the size and location of bleeding, were not available. As mentioned earlier, these data do not allow for the discrimination of comorbidities existing before the onset of $\mathrm{SDH}$, and also do not allow for neurological examination outside of the variables of delirium and coma. NSQIP data are limited to the first 30 postoperative days, so late adverse events are not considered. Mortality in this largely elderly patient population likely includes some death from causes unrelated to SDH and surgical evacuation. Because the NSQIP includes surgically treated patients only, no comparison could be made to nonoperative cases. Additionally, long-term general and functional outcomes are not available in this database. 
Approximately one-quarter of patients identified in this study had some missing data. The extent of missing data for most of these patients was minimal-typically a single missing comorbidity, outcome, or demographic detail. However, the exclusion of a substantial number of patients for missing data may have biased the results of this study.

\section{Conclusions}

Our study reveals a mortality rate of $17 \%$ associated with surgically treated $\mathrm{SDH}$, with death much more likely following surgical evacuation if the patient had overall poor general health (i.e., ascites and dialysis), a worse neurological examination (coma), and coagulopathy. More than $40 \%$ of patients with surgically treated SDH will experience an adverse event in the 30-day postoperative period. Dialysis and ventilator-dependence prior to surgery, as well as ASA Class 4 or higher, are associated with longer hospital stays and higher risk of adverse events. In the end, SDH evacuation is a common neurosurgical practice that aids and saves many patients, but we cannot forget to acknowledge and counsel our patients and families about the potential substantial risks associated with evacuation, particularly in the elderly.

\section{References}

1. American College of Surgeons: User Guide for the 2012 ACS NSQIP Participant Use Data File. (https://www.facs. org/ /media/files/quality\%20programs/nsqip/ug12.ashx) [Accessed June 16, 2015]

2. Bohl D, Basques B, Golinvaux N, Baumgaertner M, Grauer J: Nationwide Inpatient Sample and National Surgical Quality Improvement Program give different results in hip fracture studies. Clin Orthop Relat Res 472:1672-1680, 2014

3. Bohl DD, Fu MC, Golinvaux NS, Basques BA, Gruskay JA, Grauer JN: The "July effect" in primary total hip and knee" arthroplasty: analysis of 21,434 cases from the ACS-NSQIP database. J Arthroplasty 29:1332-1338, 2014

4. Busl KM, Prabhakaran S: Predictors of mortality in nontraumatic subdural hematoma. J Neurosurg 119:1296-1301, 2013

5. Dent DL, Croce MA, Menke PG, Young BH, Hinson MS, Kudsk KA, et al: Prognostic factors after acute subdural hematoma. J Trauma 39:36-43, 1995

6. Frontera JA, Egorova N, Moskowitz AJ: National trend in prevalence, cost, and discharge disposition after subdural hematoma from 1998-2007. Crit Care Med 39:1619-1625, 2011

7. Gruskay J, Fu M, Basques B, Bohl D, Buerba R, Webb M, et al: Factors affecting length of stay and complications following elective anterior cervical discectomy and fusion: A study of 2,164 patients from the ACS NSQIP database. J Spinal Disord Tech [epub ahead of print], 2014

8. Hamilton MG, Frizzell JB, Tranmer BI: Chronic subdural hematoma: the role for craniotomy reevaluated. Neurosurgery 33:67-72, 1993

9. Howard MA III, Gross AS, Dacey RG Jr, Winn HR: Acute subdural hematomas: an age-dependent clinical entity. J Neurosurg 71:858-863, 1989

10. Kalanithi P, Schubert RD, Lad SP, Harris OA, Boakye M: Hospital costs, incidence, and inhospital mortality rates of traumatic subdural hematoma in the United States. J Neurosurg 115:1013-1018, 2011

11. Khuri SF, Henderson WG, Daley J, Jonasson O, Jones RS, Campbell DA Jr, et al: Successful implementation of the Department of Veterans Affairs' National Surgical Quality Improvement Program in the private sector: the Patient Safety in Surgery study. Ann Surg 248:329-336, 2008
12. Koç RK, Akdemir H, Oktem IS, Meral M, Menkü A: Acute subdural hematoma: outcome and outcome prediction. Neurosurg Rev 20:239-244, 1997

13. Lind CRP, Lind CJ, Mee EW: Reduction in the number of repeated operations for the treatment of subacute and chronic subdural hematomas by placement of subdural drains. J Neurosurg 99:44-46, 2003

14. Markwalder TM, Steinsiepe KF, Rohner M, Reichenbach W, Markwalder H: The course of chronic subdural hematomas after burr-hole craniostomy and closed-system drainage. J Neurosurg 55:390-396, 1981

15. Missori P, Fenga L, Maraglino C, Rocchi G, Nardacci B, Calderaro G, et al: Spontaneous acute subdural hematomas. A clinical comparison with traumatic acute subdural hematomas. Acta Neurochir (Wien) 142:697-701, 2000

16. National Institutes of Health: Clinical guidelines on the identification, evaluation, and treatment of overweight and obesity in adults - the evidence report. Obes Res 6 Suppl 2:51S-209S, 1998 (Erratum in Obes Res 6:464, 1998)

17. Seelig JM, Becker DP, Miller JD, Greenberg RP, Ward JD, Choi SC: Traumatic acute subdural hematoma: major mortality reduction in comatose patients treated within four hours. N Engl J Med 304:1511-1518, 1981

18. Taussky P, Hidalgo ET, Landolt H, Fandino J: Age and salvageability: analysis of outcome of patients older than 65 years undergoing craniotomy for acute traumatic subdural hematoma. World Neurosurg 78:306-311, 2012

19. Wilberger JE Jr, Harris M, Diamond DL: Acute subdural hematoma: morbidity, mortality, and operative timing. J Neurosurg 74:212-218, 1991

20. Yanaka K, Kamezaki T, Yamada T, Takano S, Meguro K, Nose T: Acute subdural hematoma-prediction of outcome with a linear discriminant function. Neurol Med Chir (Tokyo) 33:552-558, 1993

21. Zou G: A modified Poisson regression approach to prospective studies with binary data. Am J Epidemiol 159:702-706, 2004

22. Zumkeller M, Behrmann R, Heissler HE, Dietz H: Computed tomographic criteria and survival rate for patients with acute subdural hematoma. Neurosurgery 39:708-713, 1996

\section{Disclosure}

Dr. Grauer receives personal fees for legal case reviews from Affinergy, Alphatec, Bioventus, DePuy, Harvard Clinical Research Institute, ISTO Technologies, Powered Research, Stryker, Transgenomic, Medtronic, KCI, and Smith \& Nephew outside the submitted work. This publication was made possible by the Medical Student Research Fellowship at Yale University School of Medicine.

\section{Author Contributions}

Conception and design: all authors. Analysis and interpretation of data: Lukasiewicz, Basques, Webb, Samuel. Drafting the article: Lukasiewicz, Grant. Critically revising the article: all authors. Reviewed submitted version of manuscript: Grauer, Lukasiewicz. Approved the final version of the manuscript on behalf of all authors: Grauer. Statistical analysis: Lukasiewicz. Administrative/ technical/material support: Grauer. Study supervision: Grauer.

\section{Supplemental Information}

\section{Current Affiliation}

Dr. Basques: Department of Orthopedic Surgery, Rush University Medical Center, Chicago, IL.

\section{Correspondence}

Jonathan N. Grauer, Department of Orthopaedics and Rehabilitation, Yale School of Medicine, 800 Howard Ave., New Haven, CT 06510. email: jonathan.grauer@yale.edu. 